\title{
Proceeding Paper \\ Sensors Applied to Bearing Fault Detection in Three-Phase Induction Motors ${ }^{\dagger}$
}

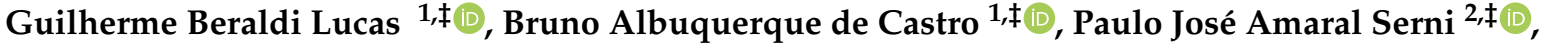 \\ Rudolf Ribeiro Riehl ${ }^{1, \ddagger(1)}$ and André Luiz Andreoli ${ }^{1, *, \mp(1)}$
}

1 Department of Electrical Engineering, School of Engineering, São Paulo State University (UNESP), Bauru 17033-360, SP, Brazil; guilherme.beraldi@unesp.br (G.B.L.); bruno.castro@unesp.br (B.A.C.); rudolf.riehl@unesp.br (R.R.R.)

2 Group of Modeling and Control of Dynamic Systems (MODCON), Institute of Science and Technology (ICTS), São Paulo State University (UNESP), Sorocaba 18087-180, SP, Brazil; paulo.serni@unesp.br

* Correspondence: andre.andreoli@unesp.br

+ Presented at the 8th International Electronic Conference on Sensors and Applications, 1-15 November 2021; Available online: https://ecsa-8.sciforum.net.

$\ddagger$ These authors contributed equally to this work.

check for updates

Citation: Lucas, G.B.; de Castr, B.A.; Serni, P.J.A.; Riehl, R.R.; Andreoli, A.L. Sensors Applied to Bearing Fault Detection in Three-Phase Induction Motors. Eng. Proc. 2021, 10, 40. https://doi.org/10.3390/ecsa-8-11319

Academic Editor: Francisco Falcone Published: 1 November 2021

Publisher's Note: MDPI stays neutral with regard to jurisdictional claims in published maps and institutional affiliations.

Copyright: (C) 2021 by the authors. Licensee MDPI, Basel, Switzerland. This article is an open access article distributed under the terms and conditions of the Creative Commons Attribution (CC BY) license (https:// creativecommons.org/licenses/by/ $4.0 /)$.

\begin{abstract}
Three-Phase Induction Motors (TIMs) are widely applied in industries. Therefore, there is a need to reduce operational and maintenance costs since their stoppages can impair production lines and lead to financial losses. Among all the TIM components, bearings are crucial in the machine operation once they couple rotor to the motor frame. Furthermore, they are constantly subjected to friction and mechanical wearing. Consequently, they represent around $41 \%$ of the motor fault, according to IEEE. In this context, several studies have sought to develop monitoring systems based on different types of sensors. Therefore, considering the high demand, this article aims to present the state of the art of the past five years concerning the sensing techniques based on current, vibration, and infra-red analysis, which are characterized as promising tools to perform bearing fault detection. The current and vibration analysis are powerful tools to assess damages in the inner race, outer race, cages, and rolling elements of the bearings. These sensing techniques use current sensors like hall effect-based, Rogowski coils, and current transformers, or vibration sensors such as accelerometers. The effectiveness of these techniques is due to the previously developed models, which relate the current and vibration frequencies to the origin of the fault. Therefore, this article also presents the bearing fault mathematical modeling for these techniques. The infra-red technique is based on heat emission, and several image processing techniques were developed to optimize bearing fault detection, which is presented in this review. Finally, this work is a contribution to pushing the frontiers of the bearing fault diagnosis area.
\end{abstract}

Keywords: bearing fault; induction motors; fault detection; review

\section{Introduction}

Nowadays, the development of monitoring systems applied to electrical machines is a challenge for industry and science. The goal is to avoid stoppages in industrial processes with punctual and planned maintenance. In this context, Three-Phase Induction Motors (TIMs) are the main focus of maintenance plans since they are widely applied as a mechanical source in the industrial process [1-4].

Among all TIMs components, bearings are crucial in the machine operation once they allow the rotary motion of the rotor while keeping it fixed to the motor structure. Due to their high degree of mobility, they are subject to different types of mechanical flaws [1,2,5]. According to [6], the TIM failures can be distributed in the bearings, rotor, stator, shaft coupling, external conditions, and other types of fault. Charts prove that the bearings are the components with the highest fault percentage (41\%) in induction motors (Figure 1). 
Bearings can be divided into four parts: outer ring, inner ring, cage, and balls (Figure 2) [7]. All parts are subject to degradation due to several factors, including operation, maintenance, handling, design, poor lubrication, and manufacturing. These factors are further detailed in Figure 3 [8]. Furthermore, these conditions can compromise the integrity of the device, increasing the vibration pattern of the machine, generating eccentricity in the rotor, and elevating the supply current [7]. Due to their relevance, bearings are the focus of predictive, preventive, and corrective maintenance.

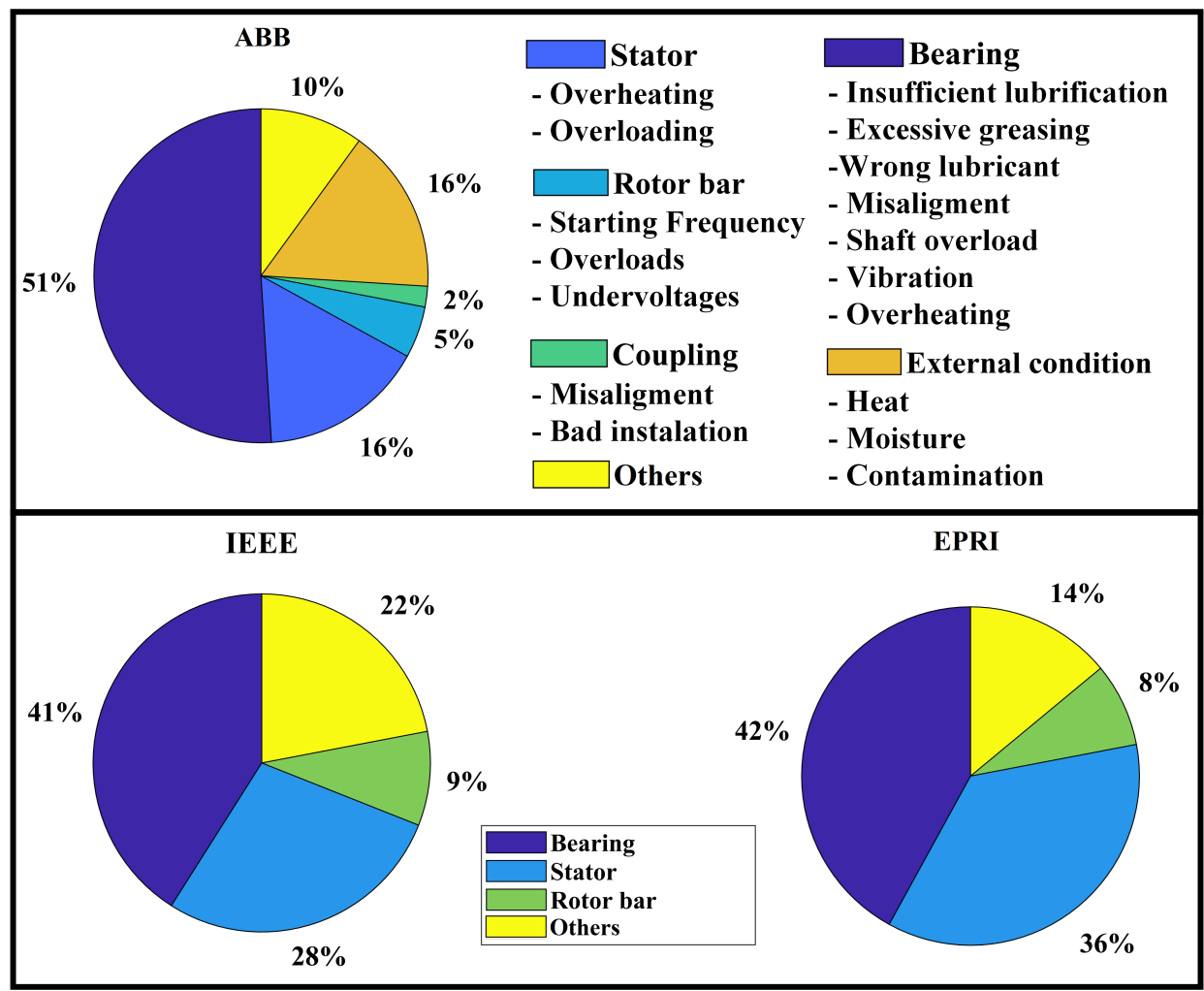

Figure 1. Faults in induction motors [6].
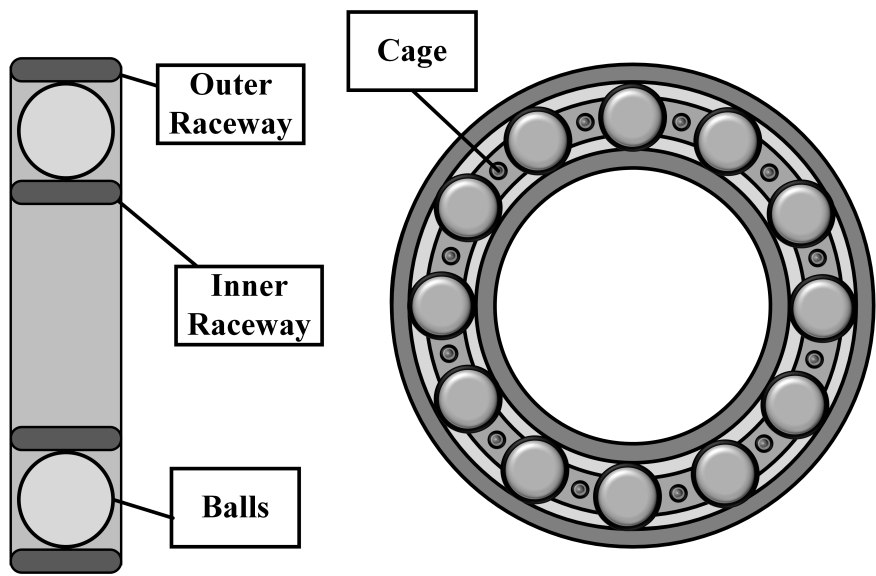

Figure 2. Bearing parts [7].

Therefore, this work presented the principal approaches for bearing fault detection: vibration, current, and thermal analysis. Additionally, the following sections describe the dynamic model of the faults for vibration and current signals. Furthermore, finally, the most recent works in this field were introduced and discussed. 


\begin{tabular}{|c|c|c|c|}
\hline \multirow{7}{*}{ } & Not enough lubricant & \multirow{6}{*}{ 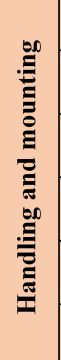 } & \multirow{2}{*}{\begin{tabular}{|l} 
Inappropriate storage conditions \\
Exposure to vibration during transport
\end{tabular}} \\
\hline & Too much lubricant & & \\
\hline & Viscosity too low & & Wrong clearance or preload setting \\
\hline & Inappropriate additives or thickener & & Wrong radial or axial preload \\
\hline & Oxidized lubricant & & Misalignment \\
\hline & Solid contaminants in the lubricant & & Damage during mounting \\
\hline & Lubricant contaminated by water & \multirow{7}{*}{ 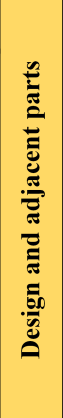 } & Geometrical form errors of shaft or housing seat \\
\hline \multirow{9}{*}{ 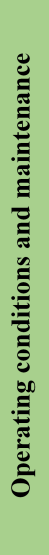 } & Static or dynamic load too high & & Inconsistent support of rings \\
\hline & Insufficient load & & Inappropriate fits and tolerances \\
\hline & Speed too high & & Ineffective seal \\
\hline & Speed too low & & Worn seals \\
\hline & Rapid changes in direction of load or rotation & & Insufficient heat removal \\
\hline & Exposure to vibration & & Difficult assemby due to design \\
\hline & Current passage, current leakage & : & Material, heat treatment \\
\hline & External heat / insufficient cooling & 表 & Machining and assembly \\
\hline & Oil filter clogged / internal contamination & $\bar{\Xi}$ & Handling \\
\hline
\end{tabular}

Figure 3. Possible causes for faults in bearings [8].

\section{Bearing Fault Detection by Vibration Analysis}

The nominal operation of TIM produces vibrations that are proportional to its rotational speed. However, the existence of non-conformities can change the vibration patterns of the machine. Therefore, vibration analysis stands out as a tool for fault diagnosis and is carried out by applying acceleration sensors $[7,9,10]$.

\subsection{Mathematical Models}

Based on the constructive elements of the bearings, the failures in this device can be found on the balls, cage, outer raceways, and inner raceways. Just as other types of faults, bearing faults are modeled from sidebands of the rotating frequency of the TIM, i.e., the frequency imposed by the angular velocity of the rotor $[9,10]$.

Considering $D_{B}$ the diameter of a ball, $D_{C O B}$ the distance between the centers of two opposite balls, $f_{r}$ the rotational frequency of the rotor, and thet $a$ the contact angle between the spheres and the raceways; the sidebands regarding to faults in balls $\left(f_{b}\right)$, cages $\left(f_{c}\right)$, outer raceways $\left(f_{\text {or }}\right)$, and inner raceways $\left(f_{i r}\right)$ are determined by the following Equations $[9,10]$ :

$$
\begin{gathered}
f_{b}=\frac{D_{\mathrm{COB}}}{2 \cdot D_{B}} \cdot f_{r} \cdot\left(1-\frac{D_{B}^{2} \cdot \cos ^{2}(\theta)}{D_{\mathrm{COB}}^{2}}\right) \\
f_{c}=\frac{1}{2} \cdot f_{r} \cdot\left(1-\frac{D_{B} \cdot \cos (\theta)}{D_{C O B}}\right) \\
f_{o r}=\frac{N_{B}}{2} \cdot f_{r} \cdot\left(1-\frac{D_{B} \cdot \cos (\theta)}{D_{C O B}}\right) \\
f_{i r}=\frac{N_{B}}{2} \cdot f_{r} \cdot\left(1+\frac{D_{B} \cdot \cos (\theta)}{D_{C O B}}\right)
\end{gathered}
$$

where $N_{B}$ is the number of balls. 


\subsection{Recent Studies}

Recent studies indicates that a critical issue to perform damage detection in bearings is the speed variation, once the mathematical model depends on the velocity of the machine.

In this scenario, Tang et al. (2020) [11], proposed an approach in which the nonstationary vibration signal was converted from the time domain into a stationary signal in the angle domain with computed order tracking to eliminate speed fluctuations [11]. Multiple bearing faults under no-load and full-load and a combination of bearing and rotor bar faults are diagnosed with Rational Dilation Wavelet Transforms (RDWT) in [9]. Ref. [12] proposed an intelligent system based on k-nearest neighbour ( $\mathrm{kNN}$ ) for diagnosing bearing defects. Hilbert Transform-based enveloping, principal component analysis (PCA), and sequential floating forward selection (SFFS) techniques were used for elimination of the redundancies, selecting the relevant features to perform bearing fault diagnosis. These selected features were the input of the kNN system.

\section{Bearing Fault Detection by Current Analysis}

Due to the operation and architecture of the TIMs, bearing faults influence the motor supply currents. Therefore, current signature analysis is a widely explored technique in recent studies for fault diagnosis.

\subsection{Mathematical Models}

As mentioned, bearing failures can be modeled according to dynamic equations. As observed in the last section, a faulty element introduces harmonics into the vibration spectrum of the machine. Additionally, any change in the vibration pattern will proportionally affect the current frequency components $[7,13]$.

Considering the vibration fault frequencies $f_{b}, f_{c}, f_{o r}$ and $f_{i r}$, as the frequency $f_{v}$, the respective fault frequency for current signals $\left(f_{I}\right)$ is given by the equation below [13]:

$$
f_{I}=\left|f \pm k \cdot f_{v}\right|
$$

where $f$ is the electrical supply frequency.

Although the frequency $f_{I}$ is essentially related to the multiple harmonics $k$ of the vibration fault frequency $f_{v}$, the use of vibration sensors is not always feasible in practice. The application of current sensors is usually more simple, cheap, and non-invasive when compared to accelerometers.

\subsection{Recent Studies}

Despite being a simple methodology, the current analysis may be subject to harmonics. Furthermore, overload operation can impair the capabilities of the methodology to identify the frequencies amplitudes and, consequently, the bearing faults. In this sense, several works try to improve the efficiency of current analysis by proposing signal processing methods.

In this context, [14] proposed a new approach to estimate the bearing fault severity based on the air-gap displacement profile. This profile was reconstructed from the mutual inductance variation, which is estimated from a quantitative electrical model that takes the stator current as input. A superposition of multiple Fourier series was used to estimate the severity of the bearing flaw [14].

Toma et al. (2020) [10] used a Genetic Algorithm and Machine Learning classifiers to perform bearing fault detection based on current analysis. Multiple characteristic vibration frequencies modulated in the current was investigated in [15], which proposed a new mathematical model considering the geometry of the damages. A remote monitoring system combined with frequency analysis was proposed by [13]. Corral et al. (2021) [16] studied three types of goodness-of-fit (GoFT) tests for current analysis to detect three types of bearing fault. 


\section{Bearing Fault Detection by Infrared Thermal Cameras}

Since bearing failures are inherently related to high temperatures, thermal analysis is frequently applied to monitor this equipment. Although its feature extraction is not as effective as other methods, its simplicity and reliability make it a widely used tool [17]. The basis of this method is to detect the infrared wavelengths emitted by bearing failures. Figure 4 [18] illustrates an image of a TIM with a faulty bearing captured by a thermal camera.

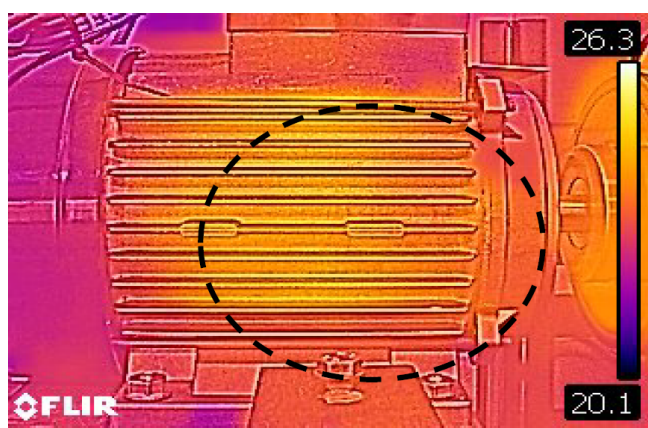

(a)

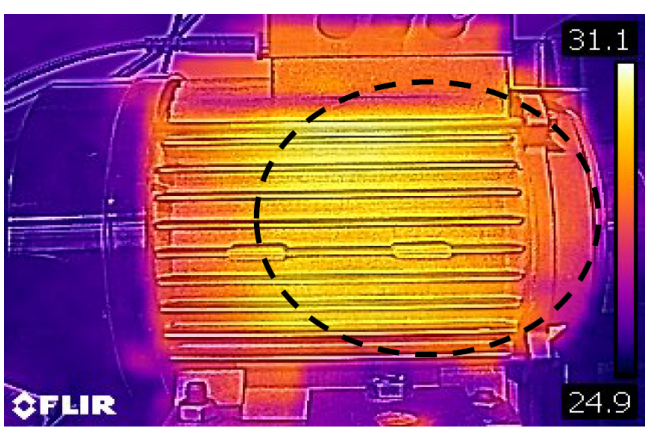

(b)

Figure 4. (a) Thermal image of a healthy TIM, (b) Thermal image of a TIM subjected to a outer raceway bearing fault [18].

\section{Recent Studies}

One of the most common issues in Infrared Thermal Analysis is the noise caused by the environment, which impairs the capabilities of distinction of heat spots. Therefore, recent studies focus on improving signal processing techniques to distinguish the heat emitted by the faults from background noise.

In [6], the discrete wavelet transform was applied for denoising the images captured from different bearing conditions under different speeds and loads. After that, Principal component analysis and Mahalanobis distance (MD) criteria were applied to perform better classification accuracy and less training time compared to conventional algorithms. Thus, PCA-MD method has been used to obtain the optimal feature set as a training classifier for bearing fault detection.

Ammar et al. (2020) [18] proposed a new approach to improve the capabilities of thermal analysis by proposing a new color model namely Hue, Saturation and Value (HSV). Five segmentation methods (Sobel, Prewitt, Roberts, Canny and Otsu) were used for segmenting the Hue region aiming to highlight the hottest area in the thermal image. After that, the Mean, Mean Square Error, Peak Signal to Noise Ratio, Variance, Standard Deviation, Skewness and Kurtosis were applied to select bearing fault conditions [18].

In [19], a histogram-based approach was used to classify the bearing condition under temperature variation. Shao et al. (2021) proposed a rotor-bearing diagnosis under rotating speeds using two-stage parameter transfer [20]. This imaging processing was based on a scaled exponential linear unit (SELU) and a modified stochastic gradient descent (MSGD), which were applied to construct an enhanced convolutional neural network.

\section{Conclusions}

In this work, it was presented the bearing fault models for current, vibration, and infrared sensors. State-of-the-art approaches were presented to assist future works to further enhance these systems, and expand the borders of fault detection technology.

Although bearing failures have been extensively investigated in recent years, there are still research gaps that must be explored. For instance, there is a need for systems that can accurately diagnose incipient failures. In addition, the precision of infrared approaches must be improved, as they are not yet able to indicate which bearing element is faulty. Low-cost alternatives for vibration sensors must be proposed as well since traditional accelerometers tend to be expensive. Finally, current sensors have proven to be less 
sensitive to mechanical bearing faults and less noise tolerant. Therefore, new sensors and signal processing techniques should be developed to overcome this drawback.

Author Contributions: Conceptualization, B.A.d.C. and G.B.L.; investigation R.R.R., G.B.L.; validation A.L.A. and P.J.A.S.; writing-original draft preparation B.A.d.C. and G.B.L.; writing-review and editing P.J.A.S.; supervision A.L.A. and B.A.d.C; project administration A.L.A. and P.J.A.S. All authors have read and agreed to the published version of the manuscript.

Funding: This research received no external funding.

Institutional Review Board Statement: Not applicable.

Informed Consent Statement: Not applicable.

Data Availability Statement: The data presented in this study are available upon reasonable request.

Conflicts of Interest: The authors declare no conflict of interest.

\section{References}

1. Pandarakone, S.E.; Mizuno, Y.; Nakamura, H. Evaluating the progression and orientation of scratches on outer-raceway bearing using a pattern recognition method. IEEE Trans. Ind. Electron. 2018, 66, 1307-1314. [CrossRef]

2. Lucena-Junior, J.A.; de Vasconcelos Lima, T.L.; Bruno, G.P.; Brito, A.V.; de Souza Ramos, J.G.G.; Belo, F.A.; Lima-Filho, A.C. Chaos theory using density of maxima applied to the diagnosis of three-phase induction motor bearings failure by sound analysis. Comput. Ind. 2020, 123, 103304. [CrossRef]

3. Lucas, G.B.; de Castro, B.A.; Rocha, M.A.; Andreoli, A.L. A new acoustic emission-based approach for supply disturbances evaluation in three-phase induction motors. IEEE Trans. Instrum. Meas. 2020, 70, 1-10. [CrossRef]

4. Glowacz, A.; Glowacz, W.; Glowacz, Z.; Kozik, J. Early fault diagnosis of bearing and stator faults of the single-phase induction motor using acoustic signals. Measurement 2018, 113, 1-9. [CrossRef]

5. Yu, H.; Ran, Y.; Zhang, G.; Li, X.; Li, B. A time-varying comprehensive dynamic model for the rotor system with multiple bearing faults. J. Sound Vib. 2020, 488, 115650. [CrossRef]

6. Choudhary, A.; Goyal, D.; Shimi, S.L.; Akula, A. Condition monitoring and fault diagnosis of induction motors: A review. Arch Comput. Methods Eng. 2019, 26, 1221-1238. [CrossRef]

7. Faiz, J.; Ghorbanian, V.; Joksimović, G. Fault Diagnosis of Induction Motors; Institution of Engineering and Technology: London, UK, 2017.

8. SKF. Bearing Damage and Failure Analysis; Technical Report; SKF Group: Gothenburg, Sweden, 2017.

9. Barusu, M.R.; Deivasigamani, M. Non-invasive vibration measurement for diagnosis of bearing faults in 3-phase Squirrel cage induction motor using microwave sensor. IEEE Sens. J. 2020, 21, 1026-1039. [CrossRef]

10. Toma, R.N.; Prosvirin, A.E.; Kim, J.M. Bearing fault diagnosis of induction motors using a genetic algorithm and machine learning classifiers. Sensors 2020, 20, 1884. [CrossRef] [PubMed]

11. Tang, G.; Wang, Y.; Huang, Y.; Liu, N.; He, J. Compound bearing fault detection under varying speed conditions with virtual multichannel signals in angle domain. IEEE Trans. Instrum. Meas. 2020, 69, 5535-5545. [CrossRef]

12. Goyal, D.; Dhami, S.; Pabla, B. Vibration response-based intelligent non-contact fault diagnosis of bearings. J. Nondestruct. Eval. Diagn. Progn. Eng. Syst. 2021, 4, 021006. [CrossRef]

13. Jung, J.; Park, Y.; Lee, S.B.; Cho, C.H.; Kim, K.; Wiedenbrug, E.J.; Teska, M. Monitoring journal-bearing faults: Making use of motor current signature analysis for induction motors. IEEE Ind. Appl. Mag. 2017, 23, 12-21. [CrossRef]

14. Zhang, S.; Wang, B.; Kanemaru, M.; Lin, C.; Liu, D.; Miyoshi, M.; Teo, K.H.; Habetler, T.G. Model-based analysis and quantification of bearing faults in induction machines. IEEE Trans. Ind. Appl. 2020, 56, 2158-2170. [CrossRef]

15. Qiu, C.; Wu, X.; Xu, C.; Qiu, X.; Xue, Z. An Approximate Estimation Approach of Fault Size for Spalled Ball Bearing in Induction Motor by Tracking Multiple Vibration Frequencies in Current. Sensors 2020, 20, 1631. [CrossRef] [PubMed]

16. Aviña-Corral, V.; Rangel-Magdaleno, J.; Morales-Perez, C.; Hernandez, J. Bearing Fault Detection in Adjustable Speed DrivePowered Induction Machine by Using Motor Current Signature Analysis and Goodness-of-Fit Tests. IEEE Trans. Ind. Inform. 2021, 17, 8265-8274. [CrossRef]

17. Choudhary, A.; Goyal, D.; Letha, S.S. Infrared thermography-based fault diagnosis of induction motor bearings using machine learning. IEEE Sens. J. 2020, 21, 1727-1734. [CrossRef]

18. Al-Musawi, A.K.; Anayi, F.; Packianather, M. Three-phase induction motor fault detection based on thermal image segmentation. Infrared Phy. Technol. 2020, 104, 103140. [CrossRef]

19. Khamisan, N.; Ghazali, K.H.; Almisreb, A.; Zin, A.H.M. Histogram-based of Healthy and Unhealthy Bearing Monitoring in Induction Motor by Using Thermal Camera. J. Telecommun. Electron. Comput. Eng. 2018, 10, 31-35.

20. Shao, H.; Li, W.; Xia, M.; Zhang, Y.; Shen, C.; Williams, D.; Kennedy, A.; De Silva, C.W. Fault diagnosis of a rotor-bearing system under variable rotating speeds using two-stage parameter transfer and infrared thermal images. IEEE Trans. Instrum. Meas. 2021, 70, 1-11. [CrossRef] 